\title{
OPTIMAL LOCATION AND SIZE OF LOGISTICS PARKS IN A REGIONAL LOGISTICS NETWORK WITH ECONOMIES OF SCALE AND $\mathrm{CO}_{2}$ EMISSION TAXES
}

\author{
Dezhi Zhang ${ }^{1}$, Richard Eglese ${ }^{2}$, Shuangyan $\mathrm{Li}^{3}$ \\ ${ }^{1}$ School of Traffic and Transportation Engineering, Central South University, Changsha Hunan, China \\ ${ }^{2}$ Dept of Management Science, Lancaster University Management School, Lancaster, United Kingdom \\ ${ }^{3}$ Forestry Engineering Doctoral Research Center, Central South University of Forestry and Technology, \\ Changsha Hunan, China
}

Submitted 17 October 2013; resubmitted 13 July 2014; accepted 25 August 2014; published online 28 January 2015

\begin{abstract}
This paper proposes a model to address the design problem of a regional logistics network. In the proposed model, the decision variables include the location and size of logistics parks. The interaction between the logistics authority and logistics users as well as the effects of economies of scale and $\mathrm{CO}_{2}$ emission taxes on the logistics network design are explicitly considered. The proposed model is formulated as a bi-level formulation, in which the upper level aims to maximize total social welfare of the system by determining the optimal location and size of logistics parks with $\mathrm{CO}_{2}$ emission taxes consideration, whereas the lower level describes the logistics users' choices for service routes. A heuristic solution algorithm is presented to solve the proposed model, and a numerical example is given to illustrate the applications of the proposed model and solution algorithm. The findings show that the optimal location and size of logistics parks depend on the realized logistics demand and the level of the economies of scale. The $\mathrm{CO}_{2}$ emission taxation can help to improve the total social welfare of the system and drive the logistics users to choose greener transportation modes.
\end{abstract}

Keywords: regional logistics network; bi-level model; logistics parks; $\mathrm{CO}_{2}$ emission taxes; economies of scale.

\section{Introduction}

Environmental issues have recently attracted considerable public attention around the world. There is a wide consensus that freight transportation is a major contributor to climate change and global warming is due to various pollution emissions. It has been shown that freight transportation contributes to about 5.5\% of global greenhouse gas emissions (McKinnon 2010). The report on $\mathrm{CO}_{2}$ emissions in 25 European countries during 1990-2005 also indicated that about $26 \%$ of total $\mathrm{CO}_{2}$ emissions in the air come from transportation. During logistics service activities, the $\mathrm{CO}_{2}$ emissions from transportation amounts to $93 \%$ of total pollution emissions, while the warehousing only covers 7\% (Decker 2011). It is, therefore, very important and urgent to create an environmentally sustainable logistics system.

Green logistics focuses on improvement of logistics service efficiency, decrease in logistics cost, and reduction in environmental externalities (e.g. $\mathrm{CO}_{2}$ ) so as to achieve a sustainable balance among economic, en- vironmental and social objectives (Dekker et al. 2012; McKinnon et al. 2010). Aronsson and Brodin (2006) showed that logistics efficiency and cost were not only related to the structure of supply chains, but also the logistics network design and logistics infrastructure. As an important component of a regional logistics system (or urban logistics system), logistics network design is a strategic issue, involving logistics facility planning and sustainable logistics management policy-making (Lindholm, Behrends 2012).

Various logistics centres have recently been established in large cities for quickly distributing freight. However, this raises many important issues, such as traffic congestion, air pollution and high energy consumption. To efficiently cope with these issues, it is proposed to combine multiple logistics centres into a logistics park. A logistics park, which is also referred to as 'logistics village' in Germany, 'distribution park' in Japan and 'logistics platform' in Spain, is a specially important component of the regional logistics network. A logistics

Corresponding author: Shuangyan Li

E-mail: lishuangyan585@sohu.com 
park implies a spatial concentration area for grouping various activities, such as transportation, distribution, warehousing, commercial trade, and other related services (such as maintenance and repair). It is also an intersection of different transport modes, and an interface between local traffic and long-distance traffic (Rodrigue et al. 2009; Wagener 2008).

Logistics parks play an important role in environmental effects (e.g. reducing $\mathrm{CO}_{2}$ emissions and air pollution) in Germany (Nobel 2010). Owing to the successful practices of logistics park operations in Germany and Japan, there is a growing trend in introducing logistics parks in some developing countries. For example, in China, the number of logistics park projects has more than tripled from 207 in 2006 to 754 in 2012 according to the survey data by the China Federation of Logistics \& Purchasing (CFLP 2012). However, there are some important problems in the planning and operation of the logistics park projects in China. For example, logistics users' behavioural responses to the project investment were seldom considered in the design of logistics parks, leading to a low usage rate of the logistics parks. Since the construction of a logistics park consumes a great deal of money and land, the number and size of the logistics parks should be carefully designed.

There are a number of studies on logistics network design in the literature. They can be classified into two major classes in terms of modelling methodology: HubSpoke location models based on classical location theory, and network equilibrium models based on spatial price equilibrium theory. As far as the Hub-Spoke location models are concerned, O'Kelly (1987) formulated the hub location problem as a quadratic integer programming model. Sender and Clausen (2011) presented a network model of wagonload traffic, which aimed to determine the hub location and size considering total cost and efficiency of the network system. Alumur et al. (2012) investigated a hub location problem from the perspective of network design, jointly considering the transportation cost and travel time, and proposed a mixed integer programming formulation. Tang et al. (2013) presented an optimization model for the location planning problem of logistics parks with variable capacity. The goal of their model was to determine the optimal locations and to allocate the customers to the logistics parks using a hybrid heuristic algorithm. Crainic et al. (2012) addressed a two-tiered freight distribution system in a big city. They presented a location-routing model to determine the optimal locations of logistics facilities (primary facilities and secondary facilities), and optimal sizes and routes for different vehicle fleets.

As far as the network equilibrium modelling approach is concerned, Friesz et al. (1983) presented some important freight network models for predicting intercity freight movement, and provided a case study about the US coal industry. Harker and Friesz (1986) reviewed the major modelling techniques that had been applied in analysing intercity freight network equilibrium, and pointed out the shortcomings of the spatial price equi- librium models. Taniguchi et al. (1999) proposed a bilevel model to determine the optimal size and location of public logistics terminals and solved the model using queuing theory and nonlinear programming techniques. Nagurney (2010b) investigated a multi-modal multicommodity problem from the perspective of supply chain equilibrium, and obtained a Nash-Cournot equilibrium solution based on Variational Inequality (VI) theory. Yamada et al. (2011) presented a network equilibrium model to integrate supply chain networks with transportation networks, taking into account the behaviour of freight carriers. Bauer et al. (2010) addressed a multi-commodity, capacitated intermodal freight transportation network planning problem, which considered greenhouse gas emissions as the primary objective. Up to now, the freight network equilibrium modelling approach has been widely applied in practical logistics network design (Crainic 2000; Crainic, Laporte 1997; Crainic et al. 2010; Crainic, Rousseau 1986; Fernandez et al. 1994; Guélat et al. 1990; Li et al. 2010).

Table 1 further summarizes the previous related studies on logistics network design problems (Alumur et al. 2012; Bauer et al. 2010; Crainic 2000; Crainic et al. 2001; Crainic, Rousseau 1986; Ham et al. 2005; Li et al. 2012; Lin, Chen 2008; O’Kelly, Bryan 1998; Powell, Sheffi 1989; Sender, Clausen 2011; Yamada et al. 2011, 2009). It indicates that the existing related studies mainly focused on minimizing transportation cost or time, and little attention has been paid to environment-related costs, and the effects of economies of scale.

Economy of scale for the construction of logistics parks refers to the phenomenon that the average construction cost per unit area for a logistics park decreases as the size of the logistics park increases (Berechman, Giuliano 1985; Li et al. 2012; Zhang 2006). Meanwhile, the economies of scale for the operation of logistics parks refers to the phenomenon that average operating cost per unit of shipment decreases as the size of the logistics park increases due to the clustering and synergetic effects among the different logistics service providers (Winkler, Seebacher 2012). It is of great importance to consider these effects in the design of the logistics parks particularly in an era of (capital and land) resource shortage and climate change.

We introduce the parameter $\rho(0<\rho \leq 1)$ to capture the effects of the scale economics of construction of logistics parks, as shown in Fig. 1. It can be seen in Fig. 1 that when $\rho=1.0$, the total fixed cost is a linear function of the scale of logistics park area, implying that the effects of the scale economies of the logistics park construction is not considered. When $0<\rho<1$, the fixed cost that results from an additional unit construction area (i.e. the marginal cost) decreases as the total size of the logistics parks increases. In particular, for a given logistics park, the smaller the value of $\rho$, the larger the scale economies, and vice versa. Hence, the parameter $\rho(0<\rho \leq 1)$ can indeed capture the effects of the scale economies of the logistics parks' construction and 
Table 1. Contributions to logistics network design problems

\begin{tabular}{|c|c|c|c|c|c|}
\hline \multirow{2}{*}{$\begin{array}{l}\text { Modelling } \\
\text { approach }\end{array}$} & \multicolumn{3}{|c|}{ Objective } & \multirow{2}{*}{ Economy of scale } & \multirow{2}{*}{ Citation } \\
\hline & Total cost & Total time & Environmental cost & & \\
\hline \multirow{2}{*}{$\begin{array}{l}\text { Hub-spoke } \\
\text { location } \\
\text { models }\end{array}$} & $\sqrt{ }$ & & & $\sqrt{ }$ & $\begin{array}{l}\text { O’Kelly, Bryan (1998); } \\
\text { Lin, Chen (2008) }\end{array}$ \\
\hline & $\sqrt{ }$ & $\sqrt{ }$ & & & $\begin{array}{l}\text { Sender, Clausen (2011); } \\
\text { Alumur et al. (2012) }\end{array}$ \\
\hline \multirow{3}{*}{$\begin{array}{l}\text { Network } \\
\text { equilibrium } \\
\text { models }\end{array}$} & $\sqrt{ }$ & $\sqrt{ }$ & & & $\begin{array}{l}\text { Ham et al. (2005); } \\
\text { Yamada et al. (2009); } \\
\text { Harker, Friesz (1986); } \\
\text { Powell, Sheff (1989); } \\
\text { Crainic et al. (2001) }\end{array}$ \\
\hline & $\sqrt{ }$ & $\sqrt{ }$ & & $\sqrt{ }$ & $\begin{array}{l}\text { Crainic, Rousseau (1986); } \\
\text { Crainic (2000); } \\
\text { Yamada et al. (2011); } \\
\text { Li et al. (2012) }\end{array}$ \\
\hline & $\sqrt{ }$ & $\sqrt{ }$ & $\sqrt{ }$ & & Bauer et al. (2010) \\
\hline
\end{tabular}

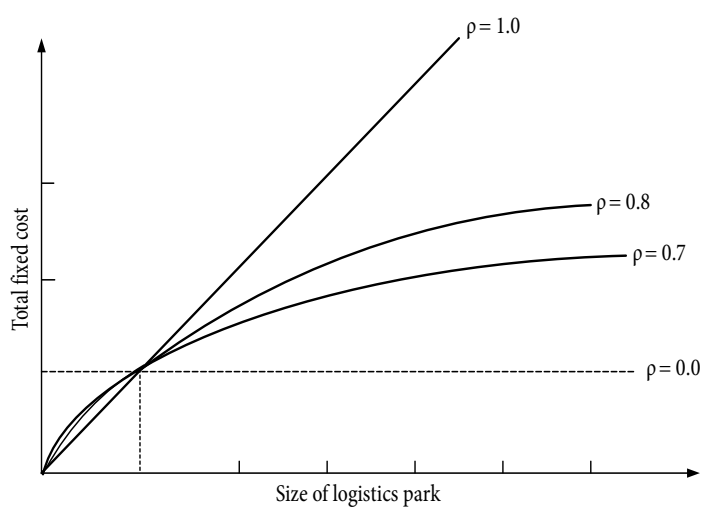

Fig. 1. The relationship between total fixed cost and size of a logistics park

operations (Berechman, Giuliano 1985; Li et al. 2012; Zhang 2006).

In view of the above, the problems to be investigated in this paper are as follows: given the alternative sites for construction of logistics parks in a region logistics network, how to decide where to locate these logistics parks, and what size each park should be? What are the effects of economies of scale on the number and size of the logistics parks? The main contributions made in this paper are twofold. First, we develop a model for simultaneously determining the optimal number and size of logistics parks in regional logistics networks, as well as the optimal $\mathrm{CO}_{2}$ emission taxes. In the proposed model, the interaction between the logistics authority and logistics users is explicitly considered, which is formulated as a bi-level model. Second, we disclose the effects of the economies of scale on the logistics network design.

The remainder of this paper is organized as follows. Section 1 describes basic components of the model, including the regional logistics network representation and model assumptions. Section 2 presents the model formulation and solution algorithm. Section 3 presents a numerical example for illustration of the model applications. Last section concludes the paper.

\section{Basic Considerations}

\subsection{Network Representation}

In order to model the regional logistics services, Fig. 2 show the logistics demand network, logistics service network, service route, and physical logistics network, respectively. In Fig. 2a, there are different types of logistics demands (such as industrial, commercial, and agricultural logistics) between a given logistics OriginDestination (OD) pair. These demands are served by the logistics service network, as shown in Fig. 2b, c.

a)

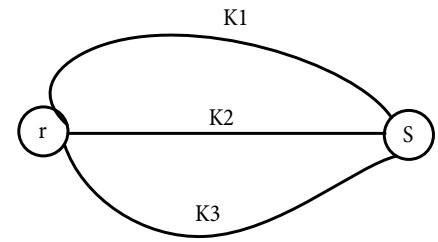

b)

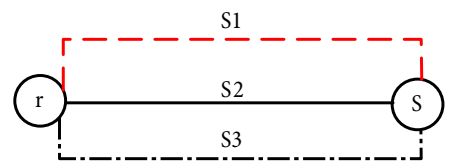

c)

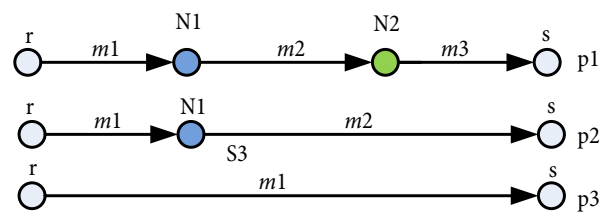

d)

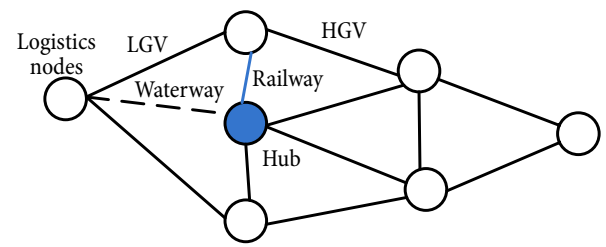

Fig. 2. Network representation of the regional logistics system: a - logistics user demand network $G_{d}=\left(N_{d}, A_{d}\right)$;

b - logistics service network $G_{s}=\left(N_{s}, A_{s}\right)$; c -logistics service route; $\mathrm{d}$ - logistics physical network $G_{p}=\left(N_{p}, A_{p}\right)$ 
Let $G_{s}=\left(N_{s}, A_{s}\right)$ denote the logistics service network (such as pick-up/delivery, storage and transfer). Let $N_{s}$ represent a set of nodes in which logistics activities are implemented. A service, denoted as $a_{s} \in A_{s}$, is defined by a logistics service route in the physical logistics network $G_{p}=\left(N_{p}, A_{p}\right)$. It consists of a sequence of logistics nodes on the service route and is differentiated by type of logistics services (such as transportation mode, service cost and service time). A logistics leg is a non-stop component of a logistics service route that is defined by itinerary, service cost and time, and transportation mode.

The logistics physical network, as shown in Fig. 2d, is composed of a set of logistics nodes (logistics parks, distribution centers, and freight terminals) and a set of logistics links or arcs, which represent physical links, such as road segments, rail tracks, river segments or sea lines. We denote a logistics physical network as $G_{p}=\left(N_{p}, A_{p}\right)$, where $N_{p}$ is the set of logistics nodes (or transfer nodes) and $A_{p}$ is the set of logistics links. All transfers take place at logistics transfer nodes. In this paper, two different types of logistics transfer nodes are considered: one is the logistics park with economy of scale effects, and the other is a general transfer node with a small capacity, such as a distribution center.

In order to facilitate the construction of the model, we introduce a virtual arc to represent a logistics transfer activity (i.e. change of transportation mode). For example, Fig. 3 represents a logistics service from node $\mathrm{A}$ to $B$, via transferring from railway to highway at transfer node $\mathrm{H}$. In this paper, for presentation purpose, we denote $N_{s}^{h} \subset N_{s}$ as the set of logistics transfer nodes and $A_{s}^{h} \subset A_{s}$ as the set of virtual logistics transfer arcs.

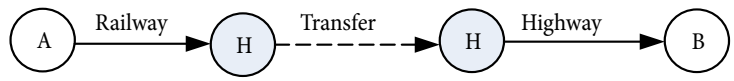

Fig. 3. Representation of virtual transfer arc

\subsection{Assumptions}

To facilitate the presentation of the essential ideas without loss of generality, the following basic assumptions are made in this paper:

A1. The planning period is assumed to be one week. The model proposed in this paper is thus mainly used for strategic planning and/or policy evaluation purposes.

A2. In the regional logistics system, the locations of logistics parks and $\mathrm{CO}_{2}$ emission taxes are determined by the logistics authority.

A3. Logistics users make their logistics service route choices based on their own perceptions of the service disutility. The disutility of logistics service is measured by service time and monetary cost. The latter consists of logistics fare and $\mathrm{CO}_{2}$ emission taxes for using this service.

A4. An elastic demand function is used to capture the responses of logistics users to the disutility of logistics service.
A5. The logistics users can use a single (pure) mode or a combination of several modes (called combined mode). The single/pure mode includes Heavy Goods Vehicle (HGV), Light Goods Vehicle (LGV), railway or waterway.

\subsection{Notations}

Sets:

$M$ - set of all transport modes in regional logitics service market, $M=M^{s} \cup M^{c}$;

$M^{s}$ - set of pure transport modes; ' 1 ', ' 2 ', ' 3 ' and ' 4 ', respectively, represent the HGV, LGV, railway, and waterway;

$M^{c}$ - set of combined transport modes;

$\mathrm{W}$ - set of all OD pairs in the logistics network;

$R_{w}=R_{w}^{s} \cup R_{w}^{c}-$ set of all service routes between OD pair $w \in W$;

$R_{w}^{s}, s \in M^{s}$ - set of routes by pure mode $s$ between OD pair $w \in W$;

$R_{w}^{c}, c \in M^{c}$ - set of routes by combined mode $c$ between OD pair $w \in W$;

$R_{w, i}^{c}, c \in M^{c}$ - set of routes by combined mode $c$ between OD pair $w \in W$ via transfer node $i$;

$I$ - set of transfer nodes; $\mathbf{S}_{i}=\left\{s_{i}^{1}, s_{i}^{2}, \cdots\right\}-$ set of alternative sizes of candidate lo-

General variables:

$q_{w}$ - realized demand between OD pair $w \in W$ [tons/week];

$q_{w}^{m}$ - realized demand between OD pair $w$, $w \in W$, serviced by transport mode $\mathrm{m}, m \in M$ [tons/week];

$q_{w, i}^{c}$ - logistics demand between OD pair $w \in W$ via transfer node $i \in I$ [tons/ week];

$t_{a}^{m}$ - transport time on arc $a \in A_{s}^{M}$ by transport mode $m$ [hour];

$\lambda_{w}$ - expected minimal disutility between OD pair $w \in W[\$]$;

$u_{w r}^{m}$ - disutility on route $r \in R_{w}$ between OD pair $w \in W$ by transport mode $m$ [\$];

$u_{w r, i}^{c}$ - disutility on route $r \in R_{w}$ between OD pair $w \in W$ by transport mode $m$, via transfer node $i \in I[\$]$;

$\delta_{a r}^{m}$ - indicator variable, equals 1 if link a is on route $r$ by mode $m$, and 0 otherwise.

Continuous decision variables (logistics users):

$h_{w r}^{m}, m \in M$ - freight flow served by combined transport mode $m$ on route $r \in R_{w}$ between OD pair $w \in W$ [tons/week];

$h_{w r}^{s}, s \in M^{s}$ - freight flow served by pure transport mode $s$ on route $r \in R_{w}^{s}$ between OD pair $w \in W$ [tons/week]; 
$h_{w r}^{c}, c \in M^{c}$ - freight flow served by combined transport mode $c$ on route $r \in R_{w}^{c}$ between OD pair $w \in W$ [tons/week];

$h_{w r, i}^{c}$ - freight flow on route $r \in R_{w}^{c}$ via transfer node $i$ between OD pair $w \in W$ [tons/ week];

$v_{a}$ - freight flow on logistics service arc $a \in A_{s}^{M} \quad$ [tons/week].

Discrete integer decision variable (logistics authority):

$y_{i}$ - size of a potential logistics park to be constructed;

$\mathbf{Y}$ - vector of variable $y_{i}, \mathbf{Y}=\left(y_{i}, \forall i \in I\right)$.

Binary decision variable (logistics authority):

$x_{i}-0-1$ variable, equals to 1 if the potential logistics node $i$ is chosen as a park and 0 otherwise;

$\mathbf{X}$ - vector of $0-1$ variable $x_{i}, \mathbf{X}=\left(X_{i}, \forall i \in I\right)$.

Constants:

$\bar{q}_{w}$ - potential demand between OD pair $w \in$ $W$ [tons/week];

$t_{a}^{m 0}$ - free flow transport service time on arc $a \in A_{s}^{M}$ by transport mode $m$ [hour];

$t_{m d}$ - average shift interval for transport mode $m$ [hour];

$l_{a}$ - length of arc $a \in A_{s}^{M}[\mathrm{~km}]$;

$c_{a}^{m}$ - fare of unit turnover on $\operatorname{arc} a \in A_{s}^{M}$ served by mode $m[\$ /$ ton-km];

$\tau_{a}^{m}$ - operator cost of unit turnover on arc $a \in A_{s}^{M}$ served by mode $m$ [\$/ton.km];

Capa $a_{a}^{m}$ - service capacity on arc $a \in A_{s}^{M}$ by mode $m$ [tons $/ \mathrm{km}]$

$\mathrm{Cap}_{i}$ - service capacity at transfer node $i \in I$ [tons/week];

$C_{i}$ - unit fare charged at logistics node $i \in I$ [\$/ton];

$C_{i}^{o}$ - unit construction cost (fixed cost) at logistics node $i \in I\left[\$ / \mathrm{m}^{2}\right]$;

$\eta_{i}$ - unit transfer operating cost at logistics node $i \in I$ [\$/ton]; $e^{m}$ - average $\mathrm{CO}_{2}$ emission per unit turnover by transport mode $m \in M[\mathrm{~kg} / \mathrm{ton} \cdot \mathrm{km}]$;

$z$ - emission taxes per unit $\mathrm{CO}_{2}$ emission $[\$ / \mathrm{kg}]$;

$\rho$ - parameter for capturing the effects of economies of scale for logistics parks;

$\beta$ - demand dispersion parameter in the elastic demand function;

$\theta$ - parameter for representing the perception variation of logistics users on logistics service disutility.

\section{Model Formulation}

In the logistics system, there are two interrelated players, namely the logistics authority and users (i.e. shippers). The goal of the logistics authority is to determine the optimal number, size and location of logistics parks so as to maximize the total social welfare of the logistics system. The decision of the logistics authority will affect the logistics users' service choices. The logistics users make their route and mode choices based on their own perceived logistics service disutility, which will further affect the logistics authority's decision. The interaction between the logistics authority and the users can be formulated as a bi-level model, as shown in Fig. 4. In the following, we in turn formulate the decisional behaviour of the logistics authority and the users.

\subsection{Logistics Users' Service Choice Equilibrium}

According to A3, the logistics users' disutility consists of the logistics service time, transportation cost, and $\mathrm{CO}_{2}$ emission taxes (if any), which can be expressed as:

$$
\begin{aligned}
& u_{w r}^{m}=C_{w r}^{m}+\tau_{v o t} T_{w r}^{m}+G_{w r}^{m}, \\
& \forall r \in R_{w}, w \in W, m \in M,
\end{aligned}
$$

where: $C_{w r}^{m}, T_{w r}^{m}$ and $G_{w r}^{m}$ represent the transportation cost, logistics service time and $\mathrm{CO}_{2}$ emission taxes on service route $r$ by transport mode $m$ between OD pair $w$, respectively; $\tau_{v o t}$ is the Value Of Time (VOT).

The transportation cost and service time on a route can be expressed as the sum of the transportation costs and service times on all the arcs along that route, in-

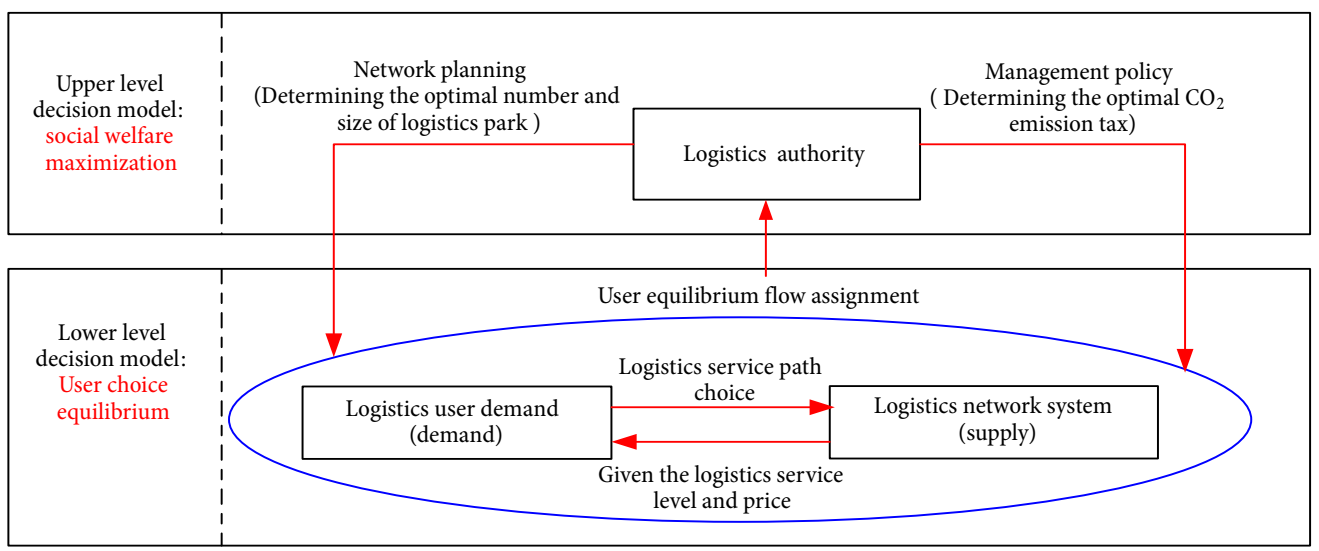

Fig. 4. The interaction between the logistics authority and the logistics users 
cluding transfer cost and time, which are, respectively, expressed as:

$$
\begin{aligned}
& C_{w r}^{m}=\sum_{a \in A_{s}} c_{a}^{m} l_{a} \delta_{a r}^{m}, \\
& \forall r \in R_{w}, w \in W, m \in M ; \\
& T_{w r}^{m}=\sum_{a \in A_{s}} t_{a}^{m}\left(v_{a}^{m}\right) \delta_{a r}^{m}, \\
& \forall r \in R_{w}, w \in W, m \in M .
\end{aligned}
$$

Considering the difference in the attributes of different transportation modes, the logistics service time on link $a$ for different modes should be estimated by different functions, as shown in Eq. (4). For the transportation mode of HGV or LGV, the Bureau of Public Roads (BPR) US type function can be used to estimate the service time (Lam et al. 1999a). For railway or waterway, the average transport service time and departure interval time should be considered, i.e.:

$$
t_{a}^{m}\left(v_{a}^{m}\right)=\left\{\begin{array}{l}
t_{a}^{m 0}\left(1+0.15\left(\frac{v_{a}^{m}}{\operatorname{Cap}_{a}^{m}}\right)^{4}\right), m=1,2, \\
t_{a}^{m 0}+t_{m d} \frac{\max \left(v_{a}^{m}-C a p_{a}^{m}, 0\right)}{\operatorname{Cap}_{a}^{m}}, m=3,4
\end{array} \quad \forall a \in A_{s}\right.
$$

where: $t_{a}^{m 0}$ is the free-flow transport service time; $t_{m d}$ is the average shift interval for transport mode $m$.

The $\mathrm{CO}_{2}$ emission taxes on route $\mathrm{r}$ between $\mathrm{OD}$ pair $\mathrm{w}$ can be expressed as the sum of the emission taxes on all the arcs along that route, i.e.:

$$
\begin{aligned}
& G_{w r}^{m}=\sum_{a \in A_{s}} e^{m} l_{a} \delta_{a r}^{m} z, \\
& \forall r \in R_{w}, w \in W, m \in M .
\end{aligned}
$$

According to A3, the logistics service mode/route choices can be calculated by a logit-based Stochastic User Equilibrium (SUE). The flow $h_{w r}^{m}$ on route $r$ between OD pair $w \in W$ served by mode $m$ can thus be given by:

$$
\begin{aligned}
& h_{w r}^{m}=q_{w} \frac{\exp \left(-\theta u_{w r}^{m}\right)}{\sum_{m \in M} \sum_{r \in R_{w}} \exp \left(-\theta u_{w r}^{m}\right)}, \\
& \forall r \in R_{w}, w \in W, m \in M,
\end{aligned}
$$

where the parameter $\theta$ represents the variation of perception of logistics users on logistics service disutility. The higher the value of $\theta$, the smaller the variation in logistics users' perception, and vice versa (Huang, Li 2007; Lam et al. 1999b; Li et al. 2007a).

In order to capture the logistics users' responses to logistics service disutility, an elastic travel demand function is introduced. It is assumed that the total resultant demand $q_{w}$ between OD pair $w$ is a continuous and monotonically decreasing function, $D_{w}(\cdot)$, of the expected minimal service disutility $\lambda_{w}$ for the logistics OD pair concerned (Sheffi 1985), i.e., in this paper, we adopt the following demand function:

$$
q_{w}=D_{w}\left(\lambda_{w}\right), \forall w \in W ;
$$

$$
q_{w}=\bar{q}_{w} \exp \left(-\beta \lambda_{w}\right),
$$

where: $\bar{q}_{w}$ is the potential logistics service demand between OD pair $w ; \beta$ is the demand dispersion parameter that reflects the demand sensitivity to the logistics service disutility by OD pair $w$. According to random utility theory, $\lambda_{w}$ can be measured by the following log-sum formula shown as Eq. (9) (Li et al. 2012; Oppenheim 1995):

$$
\lambda_{w}=-\frac{1}{\theta} \ln \left(\sum_{m \in M} \sum_{r \in R_{w}} \exp \left(-\theta u_{w r}^{m}\right)\right) .
$$

According to the theory of equilibrium network flow, the following constraints should be satisfied (Friesz et al. 1983; Sheffi 1985):

$$
\begin{aligned}
& \sum_{m \in M} q_{w}^{m}=q_{w}, \forall w \in W \\
& \sum_{r \in R_{w}} h_{w r}^{m}=q_{w}^{m}, \forall w \in W, m \in M=M^{c} \cup M^{s} \\
& \sum_{r \in R_{w, i}^{c}} h_{w r, i}^{c}=q_{w, i}^{c}, \forall i \in I, w \in W, c \in M^{c} \\
& \sum_{m \in M} \sum_{w \in W} \sum_{r \in R_{w}} h_{w r}^{m} \delta_{a r}^{m}=v_{a}, \forall a \in A \\
& h_{w r}^{s}, h_{w r}^{c}, h_{w r, i}^{c}, q_{w}^{m}, q_{w} \geq 0, \\
& \forall i \in I, w \in W, r \in R_{w}, m \in M
\end{aligned}
$$

where: Eq. (10) is the modal demand conservation constraint; Eq. (11) is the route flow conservation constraint for the pure mode or combined mode; Eq. (12) is the network flow conservation constraint regarding logistics transfer node $i$. Eq. (13) shows the relationship between the route flow and arc flow in the network; Eq. (14) shows the non-negativity constraints for the route flows and OD pairs flow respectively.

The network equilibrium for a multimodal logistics network with elastic demand can be defined as follows.

Definition 1. A network flow pattern $\left(h_{w r}^{s}, h_{w r}^{c}, h_{w r, i}^{c}, q_{w}^{m}, q_{w}\right)$ is a SUE for a multimodal logistics network with elastic demand if it satisfies Eqs (1)-(14).

\subsection{Equivalent Variational Inequality Model}

The multimodal logistics network equilibrium conditions can be formulated as an equivalent VI model.

Proposition 1. A flow pattern in a multimodal regional logistics network with elastic demand reaches the SUE state if and only if it satisfies the following VI condition:

$$
\begin{aligned}
& \sum_{w \in W} \sum_{r \in R}\left(U_{w r}^{s}+\frac{1}{\theta} \ln \frac{h_{w r}^{s^{*}}}{q_{w}^{s^{*}}}\right)\left(h_{w r}^{s}-h_{w r}^{s^{*}}\right)+ \\
& \sum_{w \in W} \sum_{r \in R}\left(U_{w r}^{c}+\frac{1}{\theta} \ln \frac{h_{w r}^{c^{*}}}{q_{w}^{c^{*}}}\right)\left(h_{w r}^{c}-h_{w r}^{c^{*}}\right)+ \\
& \sum_{w \in W} \sum_{r \in R}\left(U_{w r, i}^{c}+\frac{1}{\theta} \ln \frac{h_{w r, i}^{c^{*}}}{q_{w, i}^{c^{*}}}\right)\left(h_{w r, i}^{c}-h_{w r, i}^{c^{*}}\right)+
\end{aligned}
$$




$$
\begin{aligned}
& \sum_{w \in W} \frac{1}{\theta} \ln \frac{q_{w}^{m^{*}}}{q_{w}^{*}}\left(q_{w}^{m}-q_{w}^{m^{*}}\right)- \\
& \sum_{w \in W} \frac{1}{\beta} \ln \frac{q_{w}^{*}}{\bar{q}_{w}}\left(q_{w}-q_{w}^{*}\right) \geq 0, \\
& \forall\left(h_{w r}^{s}, h_{w r}^{c}, h_{w r, i}^{c}, q_{w}^{m}, q_{w}\right) \in \Omega,
\end{aligned}
$$

where: $\Omega$ is the feasible set of the network flow pattern $\left(h_{w r}^{s}, h_{w r}^{c}, h_{w r, i}^{c}, q_{w}^{m}, q_{w}\right)$, satisfying the constraints (11)(14). In inequality (15), $\left(h_{w r}^{s^{*}}, h_{w r}^{c^{*}}, h_{w r, i}^{c^{*}}, q_{w}^{m^{*}}, q_{w}^{*}\right)$ represents the optimal solution to the VI model; $U_{w r}^{s}, U_{w r}^{c}, U_{w r, \mathrm{i}}^{c}$ are the corresponding logistics disutility value computed at the optimal solution point $\left(h_{w r}^{s^{*}}, h_{w r}^{c^{*}}, h_{w r, i}^{c^{*}}, q_{w}^{m^{*}}, q_{w}^{*}\right)$. The proof of Proposition 1 is given in the Appendix.

\subsection{Social Welfare Maximization Model}

As previously stated, the logistics authority aims to determine the optimal number and size of the logistics parks and the optimal $\mathrm{CO}_{2}$ emission tax so as to maximize the total social welfare of the system. The total Social Welfare (SW) is defined as the sum of Consumer Surplus (CS) and producer surplus, i.e.:

$$
\begin{aligned}
& \max _{X, Y, Z} \mathrm{SW}=\left(\sum_{w \in W} \int_{0}^{q_{w}} D_{w}^{-1}(w) d w-\sum_{w \in W} q_{w} \lambda_{w}\right)+ \\
& \left(\sum_{i \in I} C_{i} h_{i}-\sum_{i \in I} C_{i}^{0}\left(y_{i}\right)^{\rho} x_{i}-\sum_{i \in I} \eta_{i} h_{i}\right)+ \\
& \left(\sum_{m \in M} \sum_{a \in A} v_{a}^{m} c_{a}^{m}-\sum_{m \in M} \sum_{a \in A} v_{a}^{m} \tau_{a}^{m}+\right. \\
& \left.\sum_{m \in M} \sum_{a \in A} v_{a}^{m} l_{a} e^{m} z\right) \\
& \text { s. t. } x_{i}=\{0,1\}, \forall i \in I \\
& y_{i} \in S_{i}, i \in I,
\end{aligned}
$$

where the network flow pattern $\left(h_{w r}^{s}, h_{w r}^{c}, h_{w r, i}^{c}, q_{w}^{m}, q_{w}\right)$ that implicitly exists in the objective function (16) can be determined by the SUE problem (10)-(15).

The objective function (16) includes three components: the first bracket represents CS, whereas the sum of the second term (i.e. the revenue at logistics nodes) and the third term (i.e. the revenue of logistics services on arcs) is the producer surplus. $D_{w}^{-1}(\cdot)$ is the inverse function of the logistics demand function. Constraint (17) expresses a binary variable with regard to the location of a logistics park, where ' 1 ' represents the decision to construct a logistics park at node $i$, and 0 otherwise. Constraint (18) represents the candidate sizes of logistics park $i$.

According to Eq. (8), one can obtain the inverse function $D_{w}^{-1}(\cdot)$ of the logistics demand function as below:

$$
D_{w}^{-1}(\cdot)=\lambda_{w}=\frac{1}{\beta} \ln \left(\frac{\bar{q}_{w}}{q_{w}}\right) .
$$

The CS can thus be represented as:

$$
\begin{aligned}
& C S=\sum_{w \in W} \int_{0}^{q_{w}} D_{w}^{-1}(w) d w-\sum_{w \in W} q_{w} \lambda_{w}= \\
& \sum_{w \in W} \int_{0}^{q_{w}} \frac{1}{\beta} \ln \left(\frac{\bar{q}_{w}}{q_{w}}\right) d\left(q_{w}\right)- \\
& \sum_{w \in W} q_{w} \frac{1}{\beta} \ln \left(\frac{\bar{q}_{w}}{q_{w}}\right)=\sum_{w \in W} \frac{q_{w}}{\beta} .
\end{aligned}
$$

\subsection{Solution Algorithm}

In this section, we develop a solution algorithm to solve the above bi-level decision model, which is based on implicit enumeration approach and the Method of Successive Average (MSA) (Geoffrion 1969; Li et al. 2012; Nguyen et al. 1998). Given the location and size of the logistics parks, then logistics users make their logistics service mode and route choices to minimize their own logistics service disutility according to Algorithm 1. On the other hand, given logistics users' decisions about logistics services, the authority can determine the location and size of the logistics parks according to Algorithm 2.

\subsubsection{Solving the Logistics User Sub-Problem at the Lower Level of the Model (Algorithm 1)}

Step 1. Initialization. Set iteration index $n=1$. Let $v_{a}^{(0)}=0, \forall a \in A$ and set the logistics service time and fare under the free-flow conditions for all links, compute the route logistics service cost, time and $\mathrm{CO}_{2}$ emission taxes $\left\{C_{w r}^{m}, T_{w r}^{m}, G_{w r}^{m}, \forall r \in R_{w}, w \in W, m \in M\right\}$ according to Eqs (2), (3) and (5).

Step 2. Calculating the disutility. Calculate the disutility of all logistics service routes $u_{w r}^{m}$ according to Eq. (1). Compute the expected minimum disutility $\lambda_{w}$ between logistics OD pair $w$ based on Eq. (9).

Step 3. Calculating logistics demand. Calculate the resultant demand for each OD pair w based on Eq. (8).

Step 4. Computing the logistics service demand, mode share and transfer flows. Use Eqs (8), (10)-(12) to compute $q_{w}^{(n)}, q_{w}^{s(n)}, q_{w}^{c(n)}$ and $q_{w, i}^{c(n)}$, respectively, where $q_{w}^{s(n)}=q_{w}^{(n)}-q_{w}^{c(n)}$.

Step 5. Logit-based SUE assignment. Conduct logit-based SUE assignment to get auxiliary link flow $g_{a}^{(n)}, a \in A$ based on Eq. (13).

Step 6. MSA. Let $v_{a}^{(n+1)}=v_{a}^{(n)}+\frac{1}{n+1}\left(g_{a}^{(n)}-v_{a}^{(n)}\right), a \in A$.

Step 7. Convergence check. Define

$\operatorname{gap}(n)=\frac{\sqrt{\sum_{a \in A}\left(v_{a}^{(n+1)}-v_{a}^{(n)}\right)^{2}}}{\sum_{a \in A} v_{a}^{(n)}}$, if $\operatorname{gap}(n) \leq \xi$, then go

to Step 9 and output all results as the final solution, where $\xi$ is a predetermined parameter. 
Step 8. Set $n=n+1$, compute all link transport costs and route transport costs on the basis of current link flows, then go to Step 2.

Step 9. Output the resultant demand and corresponding network flow pattern $h=\left(h_{w r}^{s}, h_{w r}^{c}, h_{w r, i}^{c}, q_{w}^{m}, q_{w}\right)$.

The flow chart of Algorithm 1 is shown as Fig. 5a.

\subsubsection{Solving the Logistics Authority Sub-Problem at the Upper Level of the Model (Algorithm 2)}

Let $\Omega$ be the set of decisions of the authority about the logistics park locations and $\mathrm{CO}_{2}$ emission taxes, i.e. $\Omega=\left\{\left(x_{i}^{(t)}, y_{i}^{(t)}\right), \forall t=1,2,3, \cdots, i \in I\right\}$.

Step 1. Initialization. Set $\underline{S W}=-\infty$ (i.e., the lower bound of the objective function $\overline{\mathrm{SW}}$ in Eq. (16)). Choose an initial feasible plan from government decision set $\Omega$.

Step 2. First loop operation (logistics authority implicit enumeration loop). Perform a complete logistics author-

a)

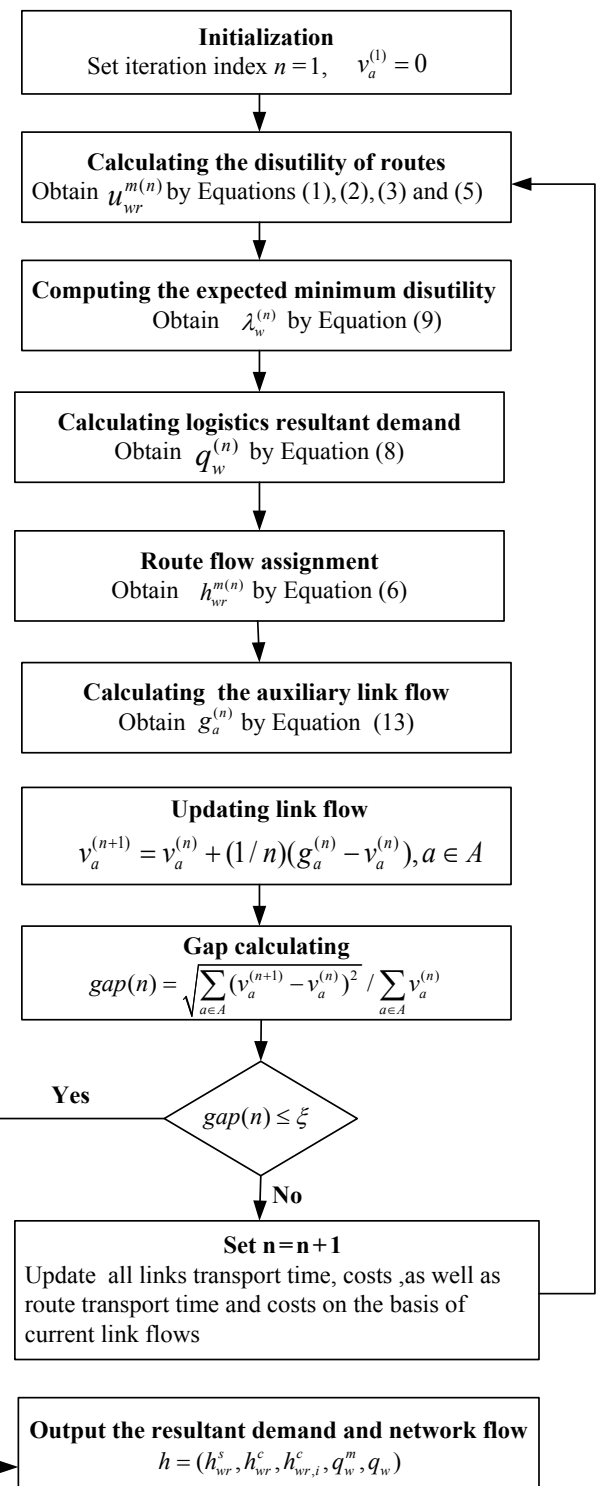

ity decision in decision set $\Omega$. Set the logistics authority decision counter to $t=1$.

Step 3. Second loop operation (logistics service route flow assignment loop). Given the logistics authority decision $\left(x_{i}^{(t)}, y_{i}^{(t)}\right)$ and the logistics service fare and service time. Solve the logistics service choice sub-model (1)-(9) using the above solution Algorithm 1 to obtain the corresponding logistics demand $q_{w}^{(t)}$ and logistics service route flow $h^{(t)}=\left\{h_{w r}^{m(t)}\right\}$, and the logistics service disutility $u^{(t)}=\left\{u_{w r}^{m(t)}\right\}$. Then, calculate the objective function value $S W^{(t)}$ for the current decision plan $\left(x_{i}^{(t)}, y_{i}^{(t)}\right)$.

Step 4. Update the objective function value. If $S W^{(j)} \geq S W$, then put $h^{*}=h^{(j)}, S W^{*}=S W^{(j)}, t=t+1$; otherwise, $t=t+1$.

Step 5. Termination check for the first loop operation. Repeat Steps 2-4 till all decision plans are retrieved and output the final solution $\left\{\left(X^{*}, Y^{*}\right), h^{*}\right)$.

The flow chart of Algorithm 2 is shown as Fig. $5 \mathrm{~b}$.

b)

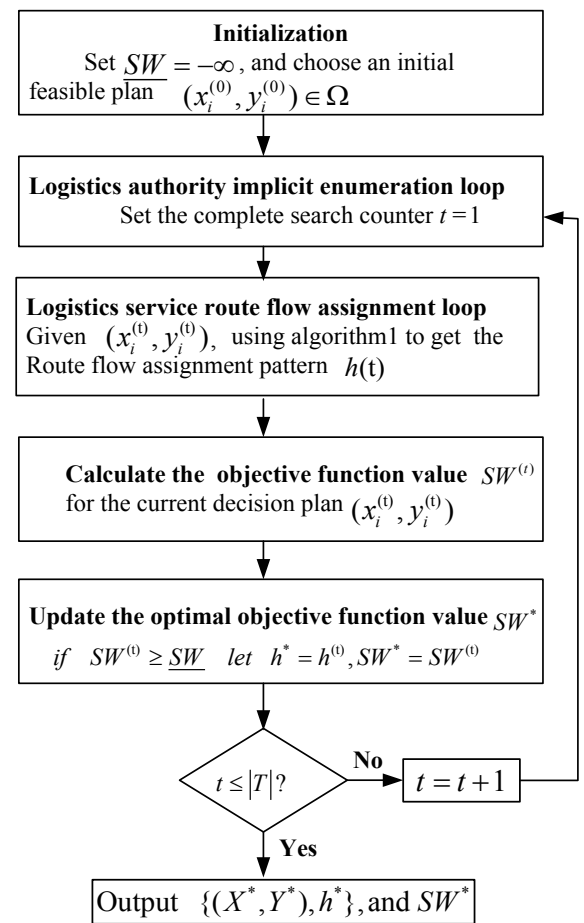

Fig. 5. The flow charts of: a - Algorithm 1; b - Algorithm 2 


\section{Illustrative Numerical Example}

\subsection{Input Data}

In the following, a numerical example is used to illustrate the applications of the proposed model and solution algorithm. The example regional logistics network is shown in Fig. 6. It consists of two logistics demand OD pairs, i.e. OD pair $1(1 \rightarrow 8)$ and OD pair $2(1 \rightarrow 7)$, eight nodes and fifteen links which are denoted by $\operatorname{arc} i(i=1$, $2,3, \ldots, 15)$. In this figure, nodes 3,4 , and 5 are assumed to be three candidate logistics parks.

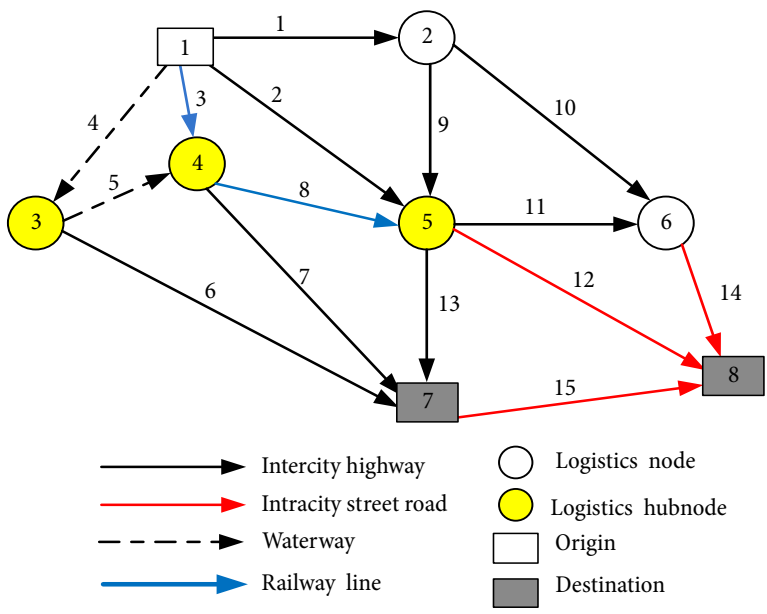

Fig. 6. The original logistics service network
Figs 6 and 7 show the original and modified logistics service networks, respectively. For some links, different vehicle types are available, and one link that is served by different vehicle types can thus be expanded as different links. For example, link 1 in the original logistics service network (i.e. Fig. 6) can be expanded as arcs 1 and 16, as shown in the modified logistics service network (i.e. Fig. 7). The basic data for the logistics service network are given in Table 2.

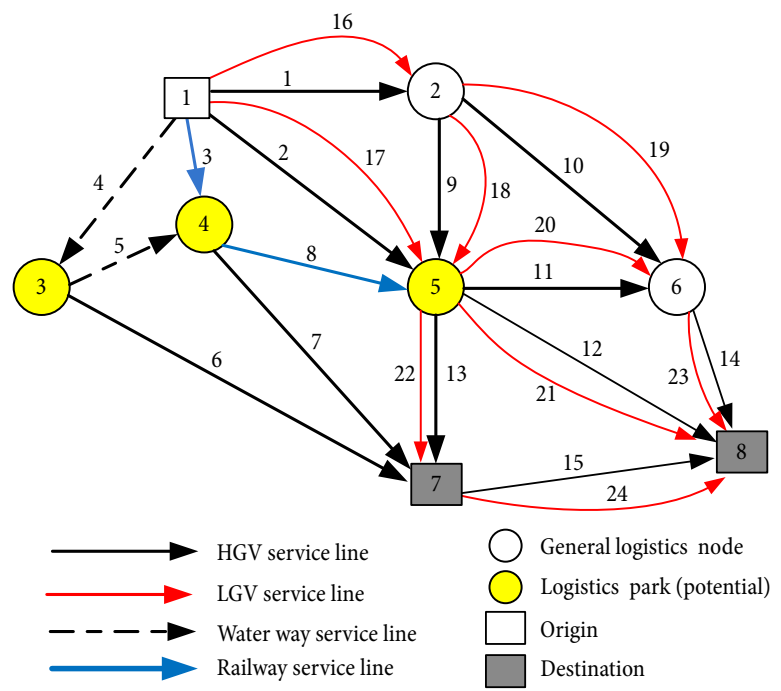

Fig. 7. The modified logistics service network

Table 2. The basic input data for the logistics service network

\begin{tabular}{ccccccc}
\hline Arc & Mode & Length $[\mathrm{km}]$ & $\begin{array}{c}\text { Free flow travel speed } \\
\text { time }[\mathrm{km} / \text { hour }]\end{array}$ & $\begin{array}{c}\text { Capacity of vehicle } \\
\text { [tons/vehicle] }\end{array}$ & $\begin{array}{c}\text { Capacity of service } \\
\text { [tons/week] }\end{array}$ & $\begin{array}{c}\text { Transport cost per unit of } \\
\text { shipment [\$/ton.km] }\end{array}$ \\
\hline 1 & HGV & 800 & 60 & 20 & 800 & 0.40 \\
\hline 2 & HGV & 1200 & 60 & 20 & 800 & 0.40 \\
\hline 3 & Railway & 1000 & 50 & 60 & 1200 & 0.30 \\
\hline 4 & Waterway & 1200 & 30 & 1500 & 1500 & 0.20 \\
\hline 5 & Waterway & 300 & 30 & 1200 & 1200 & 0.20 \\
\hline 6 & HGV & 400 & 60 & 20 & 1000 & 0.40 \\
\hline 7 & HGV & 350 & 60 & 20 & 1000 & 0.40 \\
\hline 8 & Railway & 300 & 50 & 60 & 1200 & 0.30 \\
\hline 9 & HGV & 500 & 60 & 20 & 400 & 0.40 \\
\hline 10 & HGV & 550 & 60 & 20 & 400 & 0.40 \\
\hline 11 & HGV & 80 & 60 & 20 & 400 & 0.42 \\
\hline 12 & LGV & 50 & 45 & 45 & 900 & 0.42 \\
\hline 13 & HGV & 80 & 60 & 60 & 400 & 0.42 \\
\hline 14 & LGV & 60 & 45 & 3 & 500 & 0.42 \\
\hline 15 & LGV & 40 & 45 & 3 & 600 & 0.41 \\
\hline 16 & LGV & 800 & 60 & 3 & 400 & 0.41 \\
\hline 17 & LGV & 1200 & 60 & 3 & 400 & 0.41 \\
\hline 18 & LGV & 500 & 60 & 3 & 400 & 0.41 \\
\hline 19 & LGV & 550 & 60 & 3 & 400 & 0.42 \\
\hline 20 & LGV & 80 & 60 & 3 & 400 & 0.42 \\
\hline 21 & LGV & 50 & 45 & 3 & 900 & 0.42 \\
\hline 22 & LGV & 80 & 60 & 3 & 400 & 0.42 \\
\hline 23 & LGV & 60 & 45 & 3 & 500 & 0.42 \\
\hline 24 & LGV & 40 & 45 & 3 & 600 & \\
\hline
\end{tabular}

Note: HGV - Heavy Goods Vehicle; LGV - Light Goods Vehicle. 
Suppose that the logistics OD pair 1 (from node 1 to node 8 ) serves agricultural goods with a potential demand of 1000 units per week, whereas the logistics OD pair 2 (from node 1 to node 7 ) serves industrial goods with a potential demand of 1200 units per week. The parameters $\theta$ and $\beta$ are 0.0006 and 0.02 , respectively. The VOT is $\$ 10$ per hour (De Jong et al. 2014; Guan, Kazuo 2000). The transfer cost and time at the logistics transfer node are shown in Table 3 (Qu et al. 2014; Yong 2011). The other parameters are shown in Table 4 (GB/T 21334:2008; Yong 2011). The average emissions of different transportation modes are different. Specifically, the average emissions of HGV, LGV, railway, and waterway are $0.132,0.283,0.022$, and $0.016(\mathrm{~kg} / \mathrm{ton} \cdot \mathrm{km})$ respectively (McKinnon et al. 2010; Qu et al. 2014). The parameter $z$ on $\mathrm{CO}_{2}$ emission taxes is $0.09 \$ / \mathrm{kg}$. In the following analysis, unless specifically stated otsherwise, these input data are considered as the base case.

\subsection{Numerical Results and Discussions}

The size of the optimization problem is analysed in Table 5 . The initial point for the optimization is set to be $\left\{x_{i}^{(0)}=0 ; y_{i}^{(0)}=150 ; \forall i \in I\right\}$. The proposed solution algo- rithm was coded in Microsoft Visual $C++6$ and run on a laptop Dell N5040 with an Intel Pentium 2.13 GHz CPU and 4.00 GB RAM. The CPU time for searching the corresponding optimal location and size under the different number of logistics parks is shown in Fig. 8.

Applying the proposed model and solution algorithm to the example network, the results are summarized as follows.

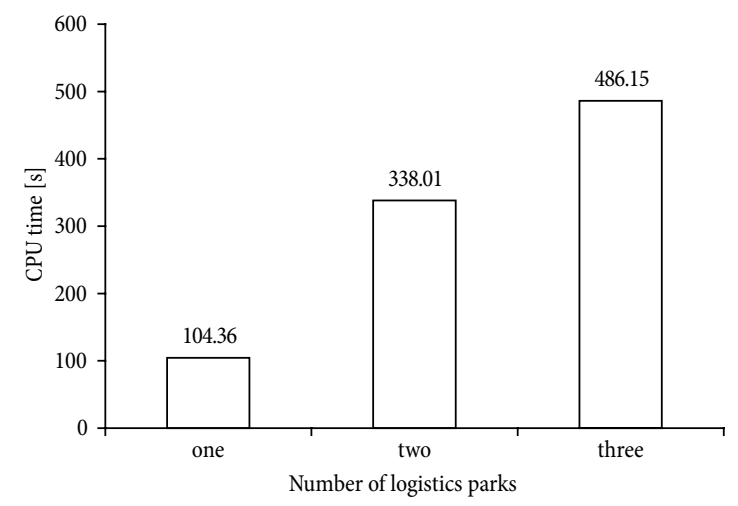

Fig. 8. CPU time for searching the optimal location and size

Table 3. The transfer time and cost at the general logistics nodes

\begin{tabular}{ccccc}
\hline Mode & HGV & LGV & Railway & Waterway \\
\hline HGV & $0(0)$ & $1.5(5)$ & $4(12)$ & $2(14)$ \\
\hline LGV & $1.5(5)$ & $0(0)$ & $3(11)$ & $1.5(13)$ \\
\hline Railway & $1.5(12)$ & $3(11)$ & $0(0)$ & $4(9)$ \\
\hline Waterway & $2(14)$ & $1.5(13)$ & $4(9)$ & $0(0)$ \\
\hline
\end{tabular}

Note: The numbers inside and outside the brackets are transfer cost [\$/ton] and transfer time [hour], respectively. Source: data adapted from Qu et al. (2014), Yong (2011).

Table 4. The transfer cost and time of logistics parks

\begin{tabular}{l|ccc|c}
\hline & \multicolumn{3}{|c|}{ Potential logistics park } & General node \\
\hline Logistics node & 3 & 4 & 5 & $N_{i}(i=1,2,6,7,8)$ \\
\hline Economy of scale factor $\rho$ & 0.9 & 0.9 & 0.9 \\
\hline $\begin{array}{l}\text { Candidate size of logistics parks } \\
\text { [tons/week] }\end{array}$ & $(600,800,1000,1400)$ & $(600,800,1000,1400)$ & $(600,800,1000,1200)$ & 150 \\
\hline $\begin{array}{l}\text { Fixed construction cost per unit } \\
\text { area of logistics node }\left[\$ / \mathrm{m}^{2}\right]\end{array}$ & 15 & 15 & 15 & 16 \\
\hline $\begin{array}{l}\text { Variable cost per unit of shipment } \\
{[\$ / \text { ton] }}\end{array}$ & 4.5 & 4.5 & 4.5 & 6 \\
\hline
\end{tabular}

Note: data adapted from GB/T 21334:2008, Yong (2011).

Table 5. Analysis on the size of the optimization problem

\begin{tabular}{|c|c|c|c|c|c|}
\hline \multicolumn{6}{|c|}{ Decision variables } \\
\hline Sub-model & \multicolumn{3}{|c|}{ Logistics user service choice equilibrium } & \multicolumn{2}{|c|}{ Social welfare maximization } \\
\hline Variables & $q_{w}$ & $h_{w r}^{m}$ & $h_{w r, i}^{c}$ & $x_{i}$ & $y_{i}$ \\
\hline Type & \multicolumn{3}{|c|}{ continuous } & binary & discrete \\
\hline Number & 2 & 92 & 64 & 8 & 32 \\
\hline
\end{tabular}

Note: The numbers of linear and nonlinear constraints are 184 and 64 respectively in this case. 


\subsubsection{Comparison of the Optimal Solutions with and without Logistics Parks}

We first compare the solutions of the models with and without logistics parks, as shown in Table 6. It can be seen in this table that for the base case, the optimal number of the logistics parks is one (i.e. node 5), with a size of 800 tons per week. Compared to the doing-nothing case (i.e. no logistic parks), the introduction of the logistics park (node 5) can lead to an increase in the logistics demand by 35 tons per week (from 1450 to 1485 tons per week), in the total social welfare by $\$ 3988$ per week (from $\$ 2178095$ to $\$ 2218083$ per week), and in market share of the combined mode by $11 \%$ (from 63 to $74 \%$ ), but a decrease in average $\mathrm{CO}_{2}$ emissions per unit of shipment by 19.50 kilogram per ton (from 166.79 to 147.29 kilogram per ton). In addition, it can also be seen in Table 6 that the introduction of the logistics park can change the flow distribution on the arcs of the network through changing the logistics users' route/mode choice behaviour.

\subsubsection{Effects of Economy of Scale Parameter $\rho$}

We now look at the impacts of the economy of scale parameter $\rho$ on the optimal number and size of the logistics parks. Fig. 9 shows that the optimal number and size of the logistics parks decrease with the increase of the value of $\rho$. Specifically, when the parameter $\rho$ is in the range $[0.70,0.75]$, all three candidate logistics parks (i.e. nodes 3, 4, and 5) are chosen. Their corresponding sizes are 800 for logistic park 3, 1200 for logistic park 5 , respectively, while the size of logistic park 4 is 1000 before the critical point 0.71 , changing to 800 after this point. When the parameter $\rho$ is in the range $[0.76,0.82]$, two candidate logistics parks are selected (i.e. nodes 4 and 5), and their corresponding sizes are 800 and 1200, respectively. However, When $\rho$ falls in the range $[0.83$, $0.85]$ and $[0.86,1.00]$ only the logistics park 5 is selected, and the corresponding optimal size of is 1000,800 respectively.

Fig. 10 shows that as the economy of scale parameter $\rho$ increases, the total social welfare decreases, but the average $\mathrm{CO}_{2}$ emissions per unit of shipment increase. This is because a larger value of $\rho$ means a higher cost for constructing and operating the logistics park. Therefore, fewer logistics parks are introduced into the system, as shown in Fig. 9. As a result, the market share of the combined mode with low $\mathrm{CO}_{2}$ emissions decreases, and thus the average $\mathrm{CO}_{2}$ emissions per unit of shipment in the network increase. Accordingly, total social welfare decreases.

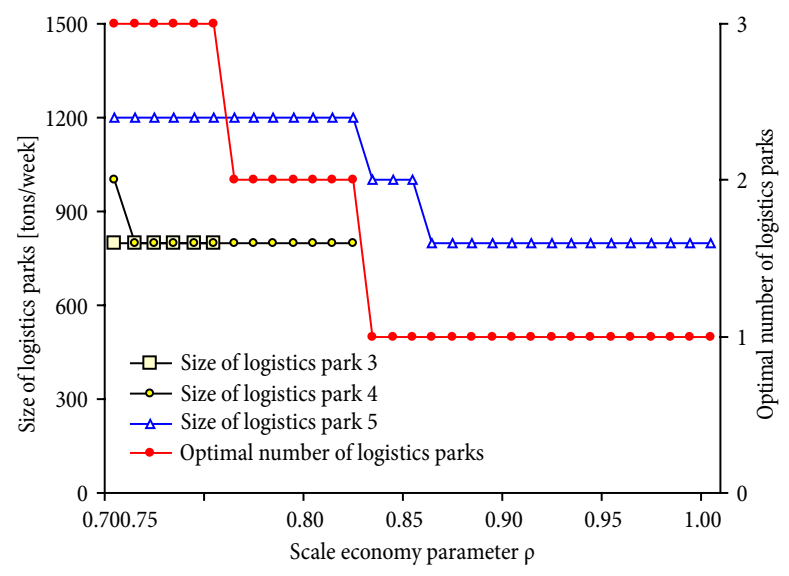

Fig. 9. Effects of economy of scale parameter $\rho$ on the optimal number and size of logistics parks

Table 6. The comparison between optimal solutions with and without logistics parks

\begin{tabular}{|c|c|c|}
\hline \multirow{2}{*}{ Arc } & \multicolumn{2}{|c|}{ Flow [tons/week] } \\
\hline & With logistics parks & Without logistics parks \\
\hline 1 & 219.66 & 239.27 \\
\hline 2 & 482.99 & 534.65 \\
\hline 3 & 512.26 & 328.57 \\
\hline 4 & 269.67 & 347.74 \\
\hline 5 & 79.44 & 72.14 \\
\hline 6 & 190.23 & 275.59 \\
\hline 7 & 153.48 & 232.62 \\
\hline 8 & 438.23 & 168.10 \\
\hline 9 & 198.54 & 213.42 \\
\hline 10 & 21.11 & 25.85 \\
\hline 11 & 91.30 & 88.66 \\
\hline 12 & 361.96 & 338.68 \\
\hline 13 & 666.51 & 488.84 \\
\hline 14 & 112.41 & 114.51 \\
\hline 15 & 209.93 & 226.85 \\
\hline Optimal number of logistics park & 1 & - \\
\hline Location of logistics park & Node 5 & - \\
\hline Size of logistics park [tons/week] & 800 & - \\
\hline Total realized demand [tons/week] & 1484.59 & 1450.23 \\
\hline Total social welfare $[\$ /$ week] & 2218083 & 2178095 \\
\hline Total customer surplus [\$/week] & 2140853 & 2096140 \\
\hline Total producer surplus [\$/week] & 77229 & 81955 \\
\hline Market share of combined mode [\%] & 74 & 63 \\
\hline $\mathrm{CO}_{2}$ emissions per unit shipment $[\mathrm{kg} / \mathrm{ton}]$ & 147.29 & 166.79 \\
\hline
\end{tabular}




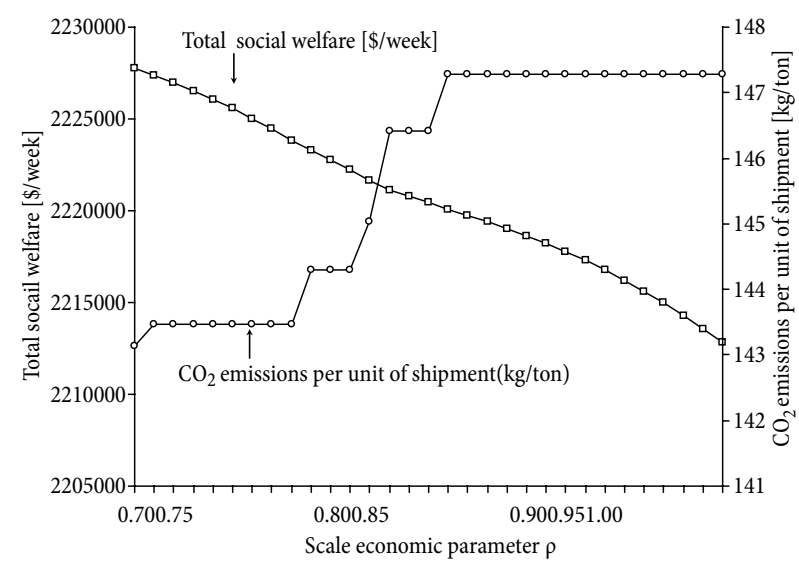

Fig. 10. Effects of economy of scale parameter $\rho$ on total social welfare and $\mathrm{CO}_{2}$ emissions per unit of shipment

\subsubsection{Effects of Logistics Demand on Optimal Number of Logistics Parks}

Fig. 11 shows the optimal numbers, locations and size of the logistics parks with various combinations of the demands of OD pairs 1 and 2 when the economy of scale parameter $\rho$ is fixed as 0.90 .

In figure, the different types of the markers represent different optimal numbers of logistics parks introduced, while the different colours of the same marker implies different size combinations for the same number. The diamond, circles, asterisk and upward-pointing triangle in this figure denote to introduce zero, one, two and three logistics parks, respectively.

In figure, the area in colourful circles represents to introduce only one logistics park (i.e. node 5), in which different colours implies different sizes. The blue, green and cyan circle indicate that the size of node 5 is 800 , 1000,1200 tons/week, respectively.

The area with markers of asterisk denotes to introduce two logistics parks (i.e. nodes 4 and 5), in which there exist four different size combinations. The blue, red, green and black asterisk represent the combinations of $(800,1000),(800,1200),(1000,1200)$ and $(1400$, $1200)$, respectively.
The area with markers of upward-pointing triangle means to introduce three logistics parks (i.e. nodes 3,4 and 5), in which there are five different size combinations, namely, $(800,800,1000),(800,1000,1200),(800$, $1400,1200),(1000,1400,1200)$ and $(1200,1400,1200)$, which are denoted by blue, red, green, black and cyan, respectively.

\subsubsection{Effects of $\mathrm{CO}_{2}$ Emission Taxes on the Logistics System}

In the following, we examine the effects of the $\mathrm{CO}_{2}$ emission taxes on the total social welfare, $\mathrm{CO}_{2}$ emissions per unit of shipment and the share of the combined mode. Fig. 12 shows that as the tax per unit of $\mathrm{CO}_{2}$ emission increases, the total social welfare first increases and then decreases, and reaches the maximum (\$2218112 per week) at the tax of $\$ 0.11$ per gram $\mathrm{CO}_{2}$ emission, which implies that charging the appropriate $\mathrm{CO}_{2}$ emission tax can help to improve the total social welfare.

Fig. 13 shows that as the $\mathrm{CO}_{2}$ emission taxes increase, the $\mathrm{CO}_{2}$ emissions per unit of shipment decrease, whereas the market share of the combined transportation mode increases. This is because the $\mathrm{CO}_{2}$ emission tax policy increases the cost of the logistics users due to an extra payment.

Table 7 further shows the effects of the $\mathrm{CO}_{2}$ emission taxes on the logistics network performance in terms of the total resultant logistics demand, total social welfare, customer surplus, producer surplus, market share of combined transport mode, and the $\mathrm{CO}_{2}$ emissions per unit of shipment. It can be seen in Table 7 that the introduction of the $\mathrm{CO}_{2}$ emission taxes can lead to a decrease in the total resultant logistics demand and the $\mathrm{CO}_{2}$ emissions per unit of shipment, but an increase in the total social welfare, the producer surplus, and the market share of the combined transport mode. Specifically, the total resultant logistics demand decreases from 1493 to 1483 tons per week, and the $\mathrm{CO}_{2}$ emissions per unit of shipment decreases from 161.65 to 144.37 kilograms per ton. However, the total social welfare increases from $\$ 2210845$ to $\$ 2218112$ per week, the producer surplus

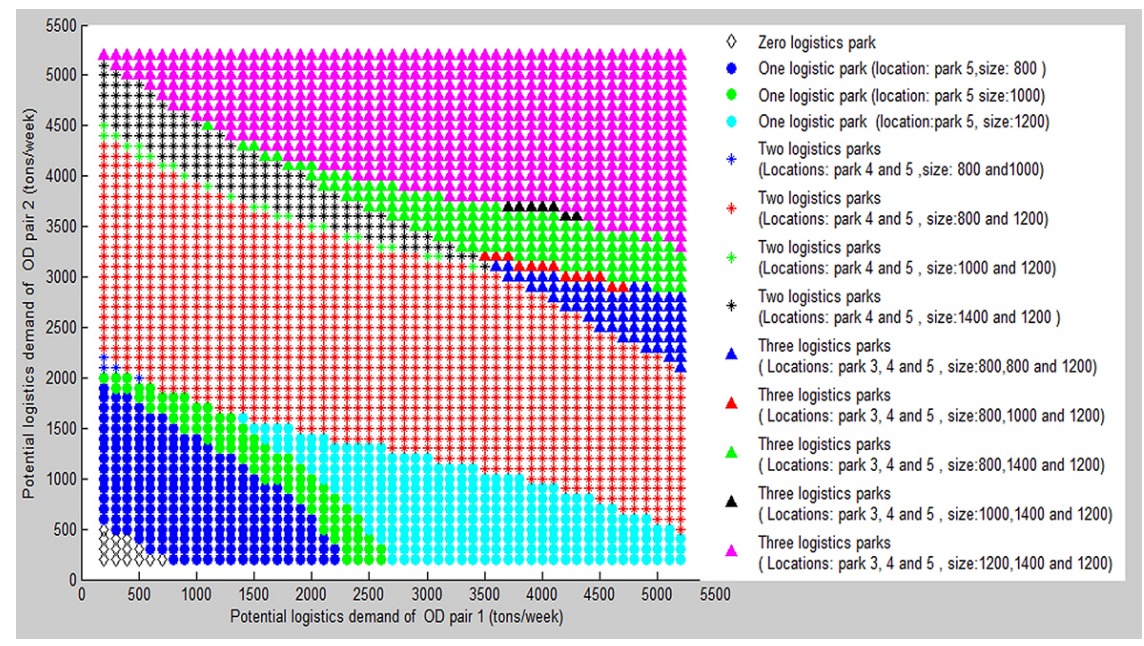

Fig. 11. Optimal number of logistics parks with different OD demand levels $(\rho=0.90)$ 


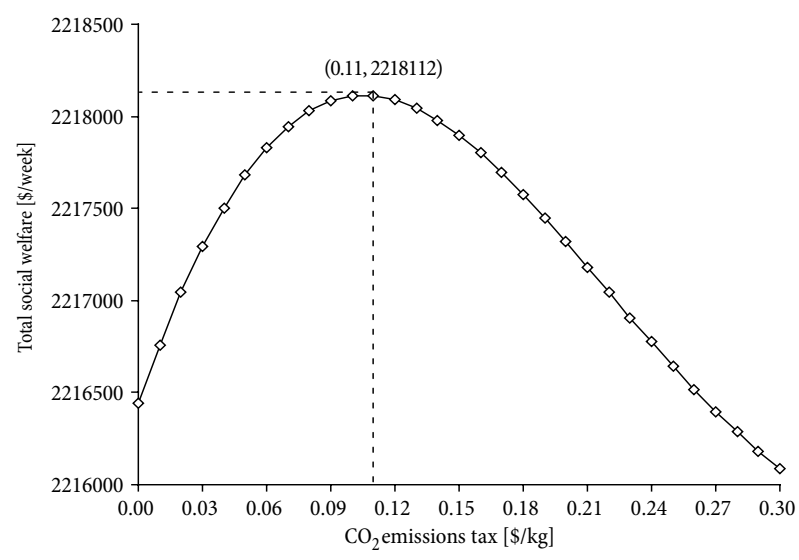

Fig. 12. Total social welfare change curve with increase of the $\mathrm{CO}_{2}$ emission tax $(\rho=0.90)$

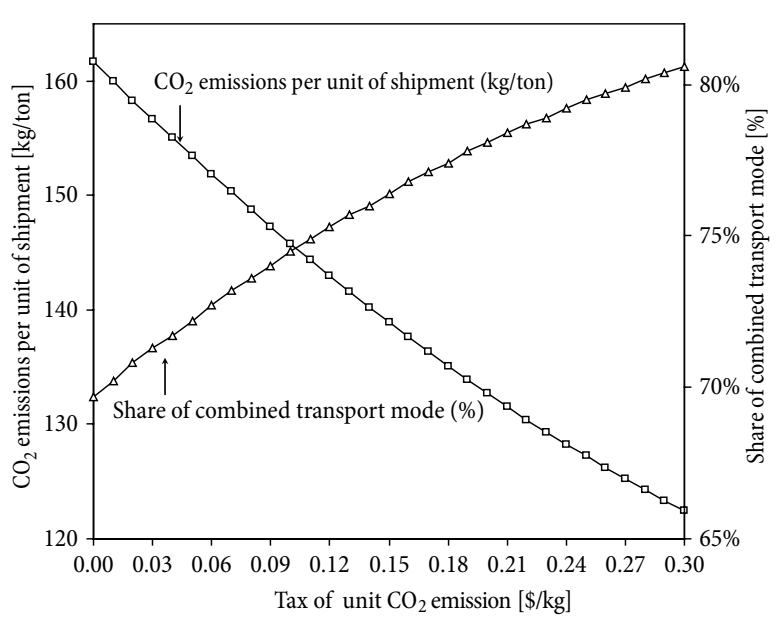

Fig. 13. Effects of $\mathrm{CO}_{2}$ emission taxes on the $\mathrm{CO}_{2}$ emissions per unit of shipment and the market share of the combined transportation mode

Table 7. Comparison of logistics network performances before and after introducing $\mathrm{CO}_{2}$ emission tax policy

\begin{tabular}{lcccccc}
\hline & $\begin{array}{c}\text { Resultant total } \\
\text { demand } \\
\text { [tons/week] }\end{array}$ & $\begin{array}{c}\text { Total social } \\
\text { welfare [\$/week] }\end{array}$ & $\begin{array}{c}\text { Customer } \\
\text { surplus } \\
{[\$ / \text { week] }}\end{array}$ & $\begin{array}{c}\text { Producer } \\
\text { surplus } \\
{[\$ / \text { week] }}\end{array}$ & $\begin{array}{c}\text { Market share } \\
\text { of combined } \\
\text { transport mode [\%] }\end{array}$ & $\begin{array}{c}\mathrm{CO}_{2} \text { emissions per } \\
\text { unit of shipment } \\
{[\mathrm{kg} / \text { ton] }}\end{array}$ \\
\hline $\begin{array}{l}\mathrm{CO}_{2} \text { emission } \\
\text { taxes [0.11 \$/kg] }\end{array}$ & 1483 & 2218112 & 2137224 & 80888.54 & 75 & 144.37 \\
\hline $\begin{array}{l}\text { Without } \mathrm{CO}_{2} \\
\text { emission taxes }\end{array}$ & 1493 & 2210845 & 2152543 & 58301.56 & 70 & 161.65 \\
\hline Change [\%] & -0.67 & 0.33 & -0.71 & 38.74 & 7.14 & -10.69 \\
\hline
\end{tabular}

increases from $\$ 58301$ to $\$ 80888$ per week, and the market share of the combined transport mode increases from 70 to $75 \%$. This implies the policy of $\mathrm{CO}_{2}$ emission taxes will improve the social welfare and induce logistics users to choose greener transport modes.

\section{Conclusion and Future Studies}

This paper proposed a new model for simultaneous optimization of the location and size of logistics parks with economies of scale and $\mathrm{CO}_{2}$ emission taxes in a multimodal regional logistics network. It was assumed that the logistics service can be completed by a pure transport mode or a combined transport mode. The logistics demand elasticity regarding logistics service level was also explicitly considered. The proposed model incorporated the interaction between the logistics authority and logistics users and also explicitly took into account the impacts of the economy of scale of the logistics parks. The proposed model was described as a bi-level model. The upper level of the model for the logistics authority was formulated as a mixed integer programming problem which can be solved by an implicit enumeration algorithm, and the lower level was formulated as a logit-based SUE problem.

Some new insights and important findings have been obtained, as follows. First, the introduction of a logistics park is closely related to the logistics demand. When the OD demand reaches some certain level, introducing a logistics park can improve the efficiency of the system in terms of social welfare and $\mathrm{CO}_{2}$ emissions per unit of shipment. Different OD demand levels can significantly affect the number and size of the logistics parks introduced. Second, the economy of scale parameter also has an important effect on the optimal number and size of the logistics parks and $\mathrm{CO}_{2}$ emissions per unit of shipment as well as the social welfare of the system. Specifically, the smaller the economy of scale parameter, the bigger the optimal number of the logistics parks due to a decrease in the construction/operating cost of the logistics system, and vice versa. Therefore, it is important for the authority to consider the effects of the economies of scale on the logistics system design. Third, the optimal emission tax policy can reduce the total amount of $\mathrm{CO}_{2}$ emissions and enhance the market share of the combined transportation mode, and thus contribute to an environmentally sustainable regional logistics service system.

It should be pointed out that, although the numerical results that are presented in this paper can be explained logically, case studies on large and realistic logistics networks are necessary to further justify the findings of this paper and the performance of the proposed model. The research directions for future studies may also focus on an extension of the proposed model to logistics network design with uncertainty in demand/supply sides, the pricing issue for a combined transportation mode in a multi-modal logistics network, the multi-period investment problem in a logistics network, and the design of an effective solution algorithm particularly for a large-scale logistics network. 


\section{Acknowledgements}

The work that is described in this paper was supported by the talented person Foundation of Central South Forestry University of Science and Technology, Forestry Engineering Postdoctoral Research Center, Central South University of Forestry and Technology, National Social Science Foundation of China (No 11CGL032), National Natural Science Foundation of China (No 7127120) and National Natural Science Foundation of China (No 71101155).

The first author is very grateful to Professor ZhiChun Li for his helpful discussions and references.

\section{References}

Alumur, S. A.; Kara, B. Y.; Karasan, O. E. 2012. Multimodal hub location and hub network design, Omega 40(6): 927939. http://dx.doi.org/10.1016/j.omega.2012.02.005

Aronsson, H.; Brodin, M. H. 2006. The environmental impact of changing logistics structures, The International Journal of Logistics Management 17(3): 394-415. http://dx.doi.org/10.1108/09574090610717545

Bauer, J.; Bektaş, T.; Crainic, T. G. 2010. Minimizing greenhouse gas emissions in intermodal freight transport: an application to rail service design, Journal of the Operational Research Society 61(3): 530-542.

http://dx.doi.org/10.1057/jors.2009.102

Berechman, J.; Giuliano, G. 1985. Economies of scale in bus transit: a review of concepts and evidence, Transportation 12(4): 313-332. http://dx.doi.org/10.1007/BF00165470

CFLP. 2012. The Third Survey Report on Logistics Parks in China. China Federation on Logistics \& Purchasing (CFLP). Available from Internet: http://www.cflp.org.cn

Crainic, T. G. 2000. Service network design in freight transportation, European Journal of Operational Research 122(2): 272-288. http://dx.doi.org/10.1016/S0377-2217(99)00233-7

Crainic, T. G.; Dufour, G.; Florian, M.; Larin, D.; Leve, Z. 2001. Demand matrix adjustment for multimodal freight networks, Transportation Research Record 1771: 140-147. http://dx.doi.org/10.3141/1771-18

Crainic, T. G.; Errico, F.; Rei, W.; Ricciardi, N. 2012. Integrating $\mathrm{C} 2 \mathrm{E}$ and $\mathrm{C} 2 \mathrm{C}$ traffic into city logistics planning, Procedia Social and Behavioral Sciences 39: 47-60. http://dx.doi.org/10.1016/j.sbspro.2012.03.090

Crainic, T. G.; Laporte, G. 1997. Planning models for freight transportation, European Journal of Operational Research 97(3): 409-438.

http://dx.doi.org/10.1016/S0377-2217(96)00298-6

Crainic, T. G.; Perboli, G.; Mancini, S.; Tadei, R. 2010b. Twoechelon vehicle routing problem: a satellite location analysis, Procedia - Social and Behavioral Sciences 2(3): 59445955. http://dx.doi.org/10.1016/j.sbspro.2010.04.009

Crainic, T. G.; Rousseau, J.-M. 1986. Multicommodity, multimode freight transportation: a general modeling and algorithmic framework for the service network design problem, Transportation Research Part B: Methodological 20(3): 225-242. http://dx.doi.org/10.1016/0191-2615(86)90019-6

De Jong, G.; Kouwenhoven, M.; Bates, J.; Koster, P.; Verhoef, E.; Tavasszy, L.; Warffemius, P. 2014. New SP-values of time and reliability for freight transport in the Netherlands, Transportation Research Part E: Logistics and Transportation Review 64: 71-87.

http://dx.doi.org/10.1016/j.tre.2014.01.008
Decker, J. 2011. Sustainability and green logistics, in Proceedings of the Joint German-Singaporean Symposium on Green Logistics, 31 August 2011, Singapoure.

Dekker, R.; Bloemhof, J.; Mallidis, I. 2012. Operations Research for green logistics - an overview of aspects, issues, contributions and challenges, European Journal of Operational Research 219(3): 671-679.

http://dx.doi.org/10.1016/j.ejor.2011.11.010

Fernandez, E.; De Cea, J.; Florian, M.; Cabrera, E. 1994. Network equilibrium models with combined modes, Transportation Science 28(3): 182-192.

http://dx.doi.org/10.1287/trsc.28.3.182

Fisk, C. S.; Boyce, D. E. 1983. Alternative variational inequality formulations of the network equilibrium-travel choice problem, Transportation Science 17(4): 454-463. http://dx.doi.org/10.1287/trsc.17.4.454

Friesz, T. L.; Tobin, R. L.; Harker, P. T. 1983. Predictive intercity freight network models: the state of the art, Transportation Research Part A: General 17(6): 409-417. http://dx.doi.org/10.1016/0191-2607(83)90161-9

GB/T 21334:2008. Classification and Fundamental Requirement of Logistics Park. Chinese Standards. (in Simplified Chinese or English).

Geoffrion, A. M. 1969. An improved implicit enumeration approach for integer programming, Operations Research 17(3): 437-454. http://dx.doi.org/10.1287/opre.17.3.437

Guan, H.-Z.; Kazuo, N. 2000. Study on estimation of the time value in freight transport, Journal of Highway and Transportation Research and Development 17(5): 107-110. (in Chinese).

Guélat, J.; Florian, M.; Crainic, T. G. 1990. A Multimode multiproduct network assignment model for strategic planning of freight flows, Transportation Science 24(1): 25-39. http://dx.doi.org/10.1287/trsc.24.1.25

Ham, H.; Kim, T. J.; Boyce, D. 2005. Implementation and estimation of a combined model of interregional, multimodal commodity shipments and transportation network flows, Transportation Research Part B: Methodological 39(1): 6579. http://dx.doi.org/10.1016/j.trb.2004.02.005

Harker, P. T.; Friesz, T. L. 1986. Prediction of intercity freight flows, I: theory, Transportation Research Part B: Methodological 20(2): 139-153. http://dx.doi.org/10.1016/0191-2615(86)90004-4

Huang, H.-J.; Li, Z.-C. 2007. A multiclass, multicriteria logitbased traffic equilibrium assignment model under ATIS, European Journal of Operational Research 176(3): 14641477. http://dx.doi.org/10.1016/j.ejor.2005.09.035

Lam, W. H. K.; Tam, M. L.; Yang, H., Wong, S. C. 1999a. Balance of demand and supply of parking spaces, in Proceedings of the 14th International Symposium on Transportation and Traffic Theory, 20-23 July 1999, Jerusalem, Israel, 707-731.

Lam, W. H. K.; Gao, Z. Y.; Chan, K. S.; Yang, H. 1999b. A stochastic user equilibrium assignment model for congested transit networks, Transportation Research Part B: Methodological 33(5): 351-368. http://dx.doi.org/10.1016/S0191-2615(98)00040-X

Li, Z.-C.; Huang, H.-J.; Lam, W. H. K.; Wong, S. C. 2007a. A model for evaluation of transport policies in multimodal networks with road and parking capacity constraints, Journal of Mathematical Modelling and Algorithms 6(2): 239257. http://dx.doi.org/10.1007/s10852-006-9040-7

Li, Z.-C.; Lam, W. H. K.; Wong, S. C.; Zhu, D.-L.; Huang, H.-J. 2007b. Modeling park-and-ride services in a multimodal 
transport network with elastic demand, Transportation Research Record 1994: 101-109.

http://dx.doi.org/10.3141/1994-14

Li, Z.-C.; Lam, W. H. K.; Wong, S. C. 2012. Optimization of number of operators and allocation of new lines in an oligopolistic transit market, Networks and Spatial Economics 12(1): 1-20. http://dx.doi.org/10.1007/s11067-010-9133-8

Li, Z.-C.; Lam, W. H. K.; Wong, S. C.; Fu, X. 2010. Optimal route allocation in a liberalizing airline market, Transportation Research Part B: Methodological 44(7): 886-902. http://dx.doi.org/10.1016/j.trb.2009.12.013

Lin, C.-C.; Chen, S.-H. 2008. An integral constrained generalized hub-and-spoke network design problem, Transportation Research Part E: Logistics and Transportation Review 44(6): 986-1003.

http://dx.doi.org/10.1016/j.tre.2008.02.001

Lindholm, M.; Behrends, S. 2012. Challenges in urban freight transport planning - a review in the Baltic Sea Region, Journal of Transport Geography 22: 129-136. http://dx.doi.org/10.1016/j.jtrangeo.2012.01.001

McKinnon, A. 2010. Green logistics: the carbon agenda, LogForum 6(3): 1-9.

McKinnon, A.; Browne, M.; Whiteing, A. 2010. Green Logistics: Improving the Environmental Sustainability of Logistics. 2nd edition. Kogan Page Ltd. 392 p.

Nagurney, A. 2010a. Network Economics: A Variational Inequality Approach. 2nd edition. Springer. 440 p.

Nagurney, A. 2010b. Supply chain network design under profit maximization and oligopolistic competition, Transportation Research Part E: Logistics and Transportation Review 46(3): 281-294. http://dx.doi.org/10.1016/j.tre.2009.11.002

Nguyen, S.; Pallottino, S.; Gendreau, M. 1998. Implicit enumeration of hyperpaths in a logit model for transit networks, Transportation Science 32(1): 54-64. http://dx.doi.org/10.1287/trsc.32.1.54

Nobel, T. 2010. Effects of Freight Villages in Germany. Institute of Shipping Economics and Logistics, Bremen, Germany. Available from Internet: http://www.isl.org/en/projects/ effects-freight-villages-germany

O'Kelly, M. E. 1987. A quadratic integer program for the location of interacting hub facilities, European Journal of Operational Research 32(3): 393-404.

http://dx.doi.org/10.1016/S0377-2217(87)80007-3

O'Kelly, M. E.; Bryan, D. L. 1998. Hub location with flow economies of scale, Transportation Research Part B: Methodological 32(8): 605-616.

http://dx.doi.org/10.1016/S0191-2615(98)00021-6

Oppenheim, N. 1995. Urban Travel Demand Modeling: From Individual Choices to General Equilibrium. Wiley. 480 p.

Powell, W. B.; Sheffi, Y. 1989. Design and implementation of an interactive optimization system for network design in the motor carrier industry, Operations Research 37(1): 12-29. http://dx.doi.org/10.1287/opre.37.1.12

Qu, Y.; Bektaş, T.; Bennell, J. 2014. Sustainability SI: multimode multicommodity network design model for intermodal freight transportation with transfer and emission costs, Networks and Spatial Economics (in press). http://dx.doi.org/10.1007/s11067-014-9227-9.

Rodrigue, J.-P.; Comtois, C.; Slack, B. 2009. The Geography of Transport Systems. 2nd edition. Routledge. 368 p.

Sender, J.; Clausen, U. 2011. A new hub location model for network design of wagonload traffic, Procedia - Social and Behavioral Sciences 20: 90-99.

http://dx.doi.org/10.1016/j.sbspro.2011.08.014
Sheffi, Y. 1985. Urban Transportation Networks: Equilibrium Analysis with Mathematical Programming Methods. Prentice Hall. 416 p.

Tang, J.; Tang, L.; Wang, X. 2013. Solution method for the location planning problem of logistics park with variable capacity, Computers \& Operations Research 40(1): 406-417. http://dx.doi.org/10.1016/j.cor.2012.07.011

Taniguchi, E.; Noritake, M.; Yamada, T.; Izumitani, T. 1999. Optimal size and location planning of public logistics terminals, Transportation Research Part E: Logistics and Transportation Review 35(3): 207-222.

http://dx.doi.org/10.1016/S1366-5545(99)00009-5

Wagener, N. 2008. The German logistics experience with freight villages - is it appropriate for the Ukraine?, in International Conference "Investments and Innovations in Logistics Infrastructure of Ukraine”, 8 April 2008, Kiev, Ukraine. Available from Internet: http://www.wagener-herbst.com/ content/news/Vortrag_NW_Kiew_20080407_V1.pdf

Winkler, H.; Seebacher, G. 2012. An empirical investigation of German freight villages, Research in Logistics \& Production 2(4): 399-410.

Yamada, T.; Imai, K.; Nakamura, T.; Taniguchi, E. 2011. A supply chain-transport supernetwork equilibrium model with the behaviour of freight carriers, Transportation Research Part E: Logistics and Transportation Review 47(6): 887-907. http://dx.doi.org/10.1016/j.tre.2011.05.009

Yamada, T.; Russ, B. F.; Castro, J.; Taniguchi, E. 2009. Designing multimodal freight transport networks: a heuristic approach and applications, Transportation Science 43(2): 129-143. http://dx.doi.org/10.1287/trsc.1080.0250

Yong, Z. 2011. Guang Zhou River Logistics Park Project Risk Management Research. South China University of Technology, China.

Zhang, D. Z. 2006. Study on the Evolvement Mechanism and Layout Optimization Methods of Logistics Park: PhD Thesis. School of Traffic and Transportation Engineering, Central South University, China. 


\section{APPENDIX}

Proposition 1. A flow pattern in a multimodal regional logistics network with elastic demand reaches the SUE state if and only if it satisfies the following VI model condition:

$$
\begin{aligned}
& \sum_{w \in W} \sum_{r \in R_{w}}\left(U_{w r}^{s}+\frac{1}{\theta} \ln \frac{h_{w r}^{s^{*}}}{q_{w}^{s^{*}}}\right)\left(h_{w r}^{s}-h_{w r}^{s^{*}}\right)+ \\
& \sum_{w \in W} \sum_{r \in R}\left(U_{w r}^{c}+\frac{1}{\theta} \ln \frac{h_{w r}^{c^{*}}}{q_{w}^{c^{*}}}\right)\left(h_{w r}^{c}-h_{w r}^{c^{*}}\right)+ \\
& \sum_{w \in W} \sum_{r \in R}\left(U_{w r, i}^{c}+\frac{1}{\theta} \ln \frac{h_{w r, i}^{c^{*}}}{q_{w, i}^{c^{*}}}\right)\left(h_{w r, i}^{c}-h_{w r, i}^{c^{*}}\right)+ \\
& \sum_{w \in W} \frac{1}{\theta}\left(\ln \frac{q_{w}^{m^{*}}}{q_{w}^{*}}\right)\left(q_{w}^{m}-q_{w}^{m^{*}}\right)- \\
& \sum_{w \in W} \frac{1}{\beta}\left(\ln \frac{q_{w}^{*}}{\bar{q}_{w}}\right)\left(q_{w}-q_{w}^{*}\right) \geq 0 ; \\
& \text { s. t. } q_{w}^{s}+q_{w}^{c}=q_{w}, \forall w \in W ; \quad\left(\lambda_{w}\right) \\
& \sum_{r \in R_{w}^{s}} h_{w r}^{s}=q_{w}^{s}, \forall w \in W ;\left(\lambda_{w}^{s}\right) \\
& \sum_{r \in R_{w}^{c}} h_{w r}^{c}=q_{w}^{c}, \forall w \in W ;\left(\lambda_{w}^{c}\right) \\
& \sum_{r \in R_{w, i}^{c}} h_{w r, i}^{c}=q_{w, i}^{c}, \forall i \in I, w \in W ;\left(\lambda_{w, i}^{c}\right) \\
& \sum_{m \in M} \sum_{w \in W} \sum_{r \in R} h_{w r}^{m} \delta_{a r}^{m}=v_{a}, \forall a \in A ; \\
& h_{w r}^{s}, h_{w r}^{c}, h_{w r, i}^{c}, q_{w}^{m}, q_{w} \geq 0, \\
& \forall i \in I, w \in W, m \in M,
\end{aligned}
$$

where: $\left(h_{w r}^{s^{*}}, h_{w r}^{c^{*}}, h_{w r, i}^{c^{*}}, q_{w}^{m^{*}}, q_{w}^{*}\right)$ represents the optimal solution to the VI model; $U_{w r}^{s}, U_{w r}^{c}, U_{w r, i}^{c}$ are the corresponding logistics disutility value computed at the optimal solution point $\left(h_{w r}^{s^{*}}, h_{w r}^{c^{*}}, h_{w r, i}^{c^{*}}, q_{w}^{m^{*}}, q_{w}^{*}\right)$.

The corresponding poof is given as follows. Let $\Omega$ denote the set of logistics service route (path) flow and logistics OD demand variables satisfying following constraints (A.2)-(A.7). And the dual variables associated with equality equations, which will be used later, are given in the brackets. Now we derive and analyse the Karush-Kuhn-Tucker (KKT) conditions of the VI (A.1), which are given below:

$$
\begin{aligned}
& \left(U_{w r}^{s}+\frac{1}{\theta} \ln \frac{h_{w r}^{s}}{q_{w}^{k s}}-\lambda_{w}^{s}\right) h_{w r}^{s}=0, \\
& U_{w r}^{s}+\frac{1}{\theta} \ln \frac{h_{w r}^{s}}{q_{w}^{s}}-\lambda_{w}^{s} \geq 0, \\
& \forall r \in R_{w}^{s}, w \in W ; \\
& \left(U_{w r}^{c}+\frac{1}{\theta} \ln \frac{h_{w r}^{c}}{q_{w}^{c}}-\lambda_{w}^{c}\right) h_{w r}^{c}=0, \\
& U_{w r}^{c}+\frac{1}{\theta} \ln \frac{h_{w r}^{c}}{q_{w}^{c}}-\lambda_{w}^{c} \geq 0,
\end{aligned}
$$

$$
\begin{aligned}
& \forall r \in R_{w}^{c}, w \in W ; \\
& \left(U_{w r, i}^{c}+\frac{1}{\theta} \ln \frac{h_{w r, i}^{c}}{q_{w}^{c}}-\lambda_{w, i}^{c}\right) h_{w r, i}^{c}=0, \\
& U_{w r}^{c}+\frac{1}{\theta} \ln \frac{h_{w r, i}^{c}}{q_{w}^{c}}-\lambda_{w, i}^{c} \geq 0, \\
& \forall r \in R_{w, i}^{c}, w \in W ; \\
& \left(\frac{1}{\theta}\left(\ln \frac{q_{w}^{m^{*}}}{q_{w}^{*}}\right)-\lambda_{w}+\lambda_{w}^{m}\right) q_{w}^{m}=0, \\
& \frac{1}{\theta}\left(\ln \frac{q_{w}^{m^{*}}}{q_{w}^{*}}\right)-\lambda_{w}+\lambda_{w}^{m} \geq 0, \\
& \forall w \in W, m \in M ; \\
& \left(-\frac{1}{\beta}\left(\ln \frac{q_{w}^{*}}{\bar{q}_{w}}\right)+\lambda_{w}\right) q_{w}=0, \\
& -\frac{1}{\beta}\left(\ln \frac{q_{w}^{*}}{\bar{q}_{w}}\right)+\lambda_{w} \geq 0, w \in W .
\end{aligned}
$$

Eqs (A.8)-(A.10) are equilibrium of logistics service route flow, shown as Eqs (A.1) and (A.2). And it is known that the output generated by logit type function is always positive, which implies that from KKT conditions (A.8)-(A.10), we have:

$$
\begin{aligned}
& h_{w r}^{s}=q_{w}^{m} \exp \left(-\theta\left(U_{w r}^{s}-\lambda_{w}\right)\right), r \in R_{w}^{s} ; \\
& h_{w r}^{c}=q_{w}^{c} \exp \left(-\theta\left(U_{w r}^{c}-\lambda_{w}\right)\right), r \in R_{w}^{c} ; \\
& h_{w r, i}^{c}=q_{w}^{c} \exp \left(-\theta\left(U_{w r, i}^{c}-\lambda_{w}^{c}\right)\right), r \in R_{w, i}^{c} .
\end{aligned}
$$

According to KKT conditions (A.11), we have:

$$
\begin{array}{r}
\text { if } q_{w}^{m}>0 \text {, then } \frac{1}{\theta}\left(\ln \frac{q_{w}^{m^{*}}}{q_{w}^{*}}\right)-\lambda_{w}+\lambda_{w}^{m}=0, \\
\text { otherwise, } \frac{1}{\theta}\left(\ln \frac{q_{w}^{m^{*}}}{q_{w}^{*}}\right)-\lambda_{w}+\lambda_{w}^{m} \geq 0 .
\end{array}
$$

In fact, $q_{w}^{m}>0$ always hold because as shown in constraints (A.4) and (A.5), they are from $h_{w r}^{m}$, which are always positive due to generating by logit type function. Therefore, we have:

$$
\frac{1}{\theta}\left(\ln \frac{q_{w}^{m^{*}}}{q_{w}^{*}}\right)-\lambda_{w}+\lambda_{w}^{m}=0, w \in W, m \in M .
$$
yields:

Combining Eq. (A.17) with conservation Eq. (A.2)

$$
1=\exp \left(\theta \lambda_{w}\right) \sum_{w \in W} \sum_{m \in M} \exp \left(-\theta \lambda_{w}^{m}\right) .
$$

From Eq. (18), we can get:

$$
\lambda_{w}=-\frac{1}{\theta} \ln \left(\sum_{r \in R_{w}} \sum_{m \in M} \exp \left(-\theta \lambda_{w r}^{m}\right)\right) .
$$

Clearly, the above Eq. (A.19) is equivalent to Eq. (9) of the logistics service choice equilibrium submodel. 
Combining Eqs (A.5), (A.9) and (A.18) with conservation Eq. (A.2), we can get:

$$
\begin{aligned}
& h_{w r}^{m}=q_{w} \frac{\exp \left(-\theta \lambda_{w r}^{m}\right)}{\sum_{m \in M} \sum_{r \in R_{w}^{m}} \exp \left(-\theta \lambda_{w r}^{m}\right)}, \\
& \forall r \in R_{w}^{m}, w \in W, m \in M .
\end{aligned}
$$

Eq. (A.20) is equivalent to Eq. (6) of the logistics service choice equilibrium sub-model, which is a logitbased logistics service mode split formulation.

Finally, we verify the logistics demand elasticity over the whole logistics service market. This can be done through checking the KKT condition (A.12). Clearly, we have:

if $q_{w}>0$, then $\lambda_{w}=\frac{1}{\beta}\left(\ln \frac{q_{w}^{*}}{\bar{q}_{w}}\right)$,

otherwise, $\lambda_{w} \geq \frac{1}{\beta}\left(\ln \frac{q_{w}^{*}}{\bar{q}_{w}}\right)$.

We can get from Eq. (A.21):

$q_{w}=\bar{q}_{w} \exp \left(-\beta \lambda_{w}\right)$.

Therefore, the overall demand elasticity has been captured by the VI formulation (A.1).

Up to here, we have shown that the proposed VI formulation (A.1) really recovers all model components presented in logistics service choice equilibrium submodel. Concerning the existence and uniqueness of the VI Eq. (A.1) solution, relevant discussions are the same with those about the fixed point, so omitted here (Fisk, Boyce 1983; Li et al. 2007b). Nagurney (2010a) showed that VI problems have unique solutions when some monotonic conditions are satisfied. 